\title{
LA COLECCIÓN ARTÍSTICA DE LOS MARQUESES DE VILLAFRANCA DEL BIERZO EN EL SIGLO XVIII ${ }^{1}$
}

\author{
THE ARTISTIC COLECTION OF THE MARQUISES OF \\ VILLAFRANCA DEL BIERZO IN THE XVIII ${ }^{\text {th }}$. CENTURY
}

\author{
FÁTIMA HALCÓN \\ Universidad de Sevilla. España \\ ORCID: 0000-0001-6045-4694 \\ fhao@us.es
}

\begin{abstract}
El marquesado de Villafranca del Bierzo constituye un ejemplo del coleccionismo de la nobleza hispánica desde el siglo XVI. La relevancia de la colección comenzó con Pedro de Toledo (1484-1553), II marqués de Villafranca del Bierzo, manteniéndose a lo largo de los siglos XVII y XVIII. Durante ese tiempo se amplió por compras, encargos y una ventajosa política matrimonial. En este artículo se dan a conocer datos inéditos de la colección en el siglo XVIII a través de las figuras de Fadrique Vicente Álvarez de Toledo Osorio y Moncada y de su hijo Antonio Álvarez de Toledo Osorio, IX marqués y $\mathrm{X}$ marqués de este título, respectivamente.

Palabras clave: pintura; tapices; colecciones artísticas; IX y X marqueses de Villafranca del Bierzo.
\end{abstract}

The marquisate of Villafranca del Bierzo is one example of the Hispanic nobility collecting since the XVIth century. The relevance of the collection began whit Pedro de Toledo (1484-1553) II marquis of Villafranca del Bierzo remaining throughout the XVII ${ }^{\text {th }}$ and XVIII ${ }^{\text {th }}$ centuries. During this time it was extended by purchases, orders and advantageous marriage policy. In this article unpublished data from the collection in the XVIII ${ }^{\text {th }}$ century through the figures of Fadrique Álvarez de Toledo Osorio y Moncada and his son Antonio Álvarez de Toledo Osorio, IX marqués y X marquis of this title, respectively.

Keywords: painting; trapestry; artistic colections; IX y X marquises of Villafranca del Bierzo.

${ }^{1}$ El presente trabajo es el resultado del proyecto I+D, El despliegue artístico de la monarquía hispánica, siglos XVI-XVIII, financiado por el Ministerio de Ciencia e Innovación y Universidades del Gobierno de España, PGC2018-093808. 
El marquesado del Villafranca del Bierzo fue uno de los títulos más relevantes de la Corona de Castilla desde los inicios de la Edad Moderna. Miembros de esta casa nobiliaria sirvieron a la monarquía hispánica a través de diferentes cargos en España y en el extranjero, otorgándoseles distintas condecoraciones y pertenencias a órdenes militares ${ }^{2}$. Su afición al arte, sus destinos en el extranjero y sus enlaces matrimoniales con personas de otros linajes enriquecieron la colección, atesorando un importante repertorio de pinturas, tapices y objetos artísticos ${ }^{3}$. La historiografía moderna ha estudiado a alguno de los miembros más notables de esta familia desde el punto de vista artístico, destacando el caso del virrey de Nápoles, Pedro de Toledo (1484-1553) ${ }^{4}$, II marqués de Villafranca del Bierzo, y la de su homónimo Pedro de Toledo (1556-1627)5, V marqués, gobernador de Milán y Capitán General de las Galeras de Nápoles, ambos de gusto refinado, grandes coleccionistas de objetos y bibliotecas.

La colección artística sufrió diversas contingencias y traslados a lo largo del tiempo, conservando un valioso repertorio de obras, incrementado en el siglo XVIII a través de ventajosos enlaces matrimoniales. En este artículo queremos dar a conocer nuevos datos de la colección a través de la figura de uno de sus miembros, Fadrique Vicente Álvarez de Toledo Osorio, IX marqués de este título (1686-1753). A través de su inventario de bienes post mortem podemos distinguir las obras procedentes de la casa de Villafranca del Bierzo de otras llegadas a la familia a través de matrimonios. La casa nobiliaria mantiene su esplendor durante el siglo XVIII, aunque no se llevaron a cabo grandes encargos artísticos como sí pueden rastrearse en épocas anteriores. La casa de Villafranca del Bierzo quedará integrada por herencia en el ducado de Medina Sidonia y por matrimonio en el de Alba a través del enlace de José Álvarez de Toledo Osorio (1756-1796), XI marqués de Villafranca del Bierzo con María Teresa de Silva Álvarez de Toledo (1762-1802), XIII duquesa de Alba, celebrado en 1775.

Si bien la familia poseía bienes artísticos desde los orígenes del marquesado (1486), la colección se enriqueció en el siglo XVI con Pedro de Toledo (14841553), II marqués consorte de Villafranca del Bierzo y virrey de Nápoles, (Figura 1). Con él comienza el interés de la familia por obras artísticas italianas. Las importantes intervenciones arquitectónicas de Pedro de Toledo en la ciudad partenopea $^{6}$ favorecieron los encargos y la compra de obras para decorar sus

${ }^{2}$ Sosa, 1676. El libro da a conocer los antecedentes familiares de los marqueses de Villafranca, árboles genealógicos y conexiones con las principales familias nobiliarias españolas.

${ }^{3}$ González Ramos, 2007: 3-35. Rubio Pérez, 2007: 57-84.

${ }^{4}$ Sobre el tema ver Hernando Sánchez, 1988: 13-33; 1993: 35-55; 1994: 87-92.

5 Estella, 2008: 219-232. Campos Sánchez-Bordona, 2007: 150-173.

${ }^{6}$ Pane, 1979: 81-95. Estella, 2008: 219-232. Hernando Sánchez, 1988: 13-33; 1993: 35 55. Bosch Balbona, 2016: 653-705. 
palacios y fundaciones religiosas además de adquirir objetos preciosos que tenían como destino obsequiar al rey de España ${ }^{7}$. Parte de la colección se vendió tras su muerte, aunque la familia seguía conservando la mayoría de los bienes en la segunda mitad del siglo XVI. Pedro de Toledo no hizo más que seguir la tradición coleccionista puesta de moda en la sociedad española desde la época de Carlos V, costumbre que copiaron las grandes casas nobiliarias ${ }^{8}$.

Desde el siglo XVI contó con una importante colección de tapices entre los que destacaron ocho tapicerías de Malta y una serie de la Historia de José que se trasladaron en 1602 desde el palacio de Villafranca del Bierzo ${ }^{9}$ al palacio de Valladolid donde pensaron fijar su residencia, siguiendo los pasos de la corte ${ }^{10}$. Este repertorio fue ampliado por el V marqués, Pedro de Toledo y Colonna (15461627), figura clave de la política española en Italia, nieto del mítico virrey de Nápoles y gran coleccionista ${ }^{11}$. El V marqués (Figura 2) encargó tapices, en su mayor parte, a los talleres de Flandes y compró tapicerías originales de Bruselas, muy codiciadas por los grandes entendidos de la época ${ }^{12}$. Destaca la serie de la Historia de Alejandro, una de los ciclos predilectos de la nobleza europea, la de Marco Antonio y Cleopatra, las Fábulas de Acteón y la Historia de Faetón, así como temas de historia antigua y mitológica ${ }^{13}$. Parte de estos tapices adornaron la residencia de los marqueses de Villafranca del Bierzo cuando se establecieron definitivamente en Madrid en 1608 en una casa situada cerca de San Francisco el Grande, en el barrio de las Vistillas. La colección contaba además con un relevante número de retratos y esculturas, traídos muchos de Italia, que incluía retratos familiares, pontífices (ciento seis de medio cuerpo), emperadores (doce emperadores romanos de medio cuerpo), reyes (ciento cuarenta y cuatro retratos de reyes, capitanes y otras personas) además de los célebres Ermitaños (Figura 3) encargados en Roma, pintura mitológica, bodegones, etc. La mayoría aparecen como anónimas, aunque se conoce que los retratos de emperadores fueron obra de Wenzel Cobergher. Muchas de estas obras se vendieron en la almoneda que se hizo tras el fallecimiento del $\mathrm{V}$ marqués, aunque alguna de ellas permaneció en la colección como muestran inventarios posteriores ${ }^{14}$.

En la segunda mitad del siglo XVII y durante el XVIII, la colección se enriqueció debido a distintos factores: cargos en la corte y en destinos italianos lo

7 Ver Brown, 1995

${ }^{8}$ Sobre este tema ver: Morán Turina/Checa, 1985. Serrera, 2001: 1431-1453. Urquízar Herrera, 2007: 53-60.

9 Bosch Balbona, 2013-2014: 79-106.

${ }^{10}$ Campos Sánchez-Bordona, 2008: 150-173.

${ }^{11}$ Coniglio, 1984. Bosch Balbona, 2007-2008: 127-154; 2009: 121-146.

12 García Calvo, 2010: 347-362.

${ }_{13}$ Sobre este esta ver: Ramírez Ruiz, 2012.

${ }_{14}$ Bosch Balbona, 2007-2008: 127-154. 
que posibilitó la compra de nuevas obras y la relación directa con otras casas nobiliarias a través de convenientes enlaces matrimoniales. El VI marqués de Villafranca, García de Toledo Osorio (1579-1649) desempeñó varios cargos al servicio de la monarquía hispánica durante el reinado de Felipe IV, su enfrentamiento con el conde duque de Olivares (1587-1645) le supuso el destierro en el castillo de Villaviciosa de Odón pero fue repuesto en sus cargos tras la caída del valido ${ }^{15}$. A su sucesor, Fadrique Alvarez de Toledo Osorio Ponce de León (1635-1705) se le concedió la Orden del Espíritu Santo en 1702 junto al duque de Medina Sidonia y al conde de Benavente ${ }^{16}$. Esta orden estuvo reservada inicialmente para los más altos dignatarios del reino de Francia, pero el rey Enrique IV permitió la entrada de un número limitado de reyes y señores extranjeros. Felipe $\mathrm{V}$, tras acceder al trono español, la concedió a una serie de nobles españoles en 1702 y además otorgó la Grandeza de España a títulos nobiliarios franceses y el Toisón de Oro a varios miembros de su familia y a nobles españoles ${ }^{17}$. La noticia de esta concesión a nobles españoles fue recogida por el Mercure historique et politique. ${ }^{18}$.

Con Fadrique de Toledo y Osorio (1635-1705), VII marqués, comienza el marquesado su andadura en el siglo XVIII. Fue Capitán General de Sicilia y de Nápoles, siendo nombrado 1671 virrey interino de esta ciudad. Rechazó la propuesta del virreinato de Nueva España al preferir ostentar el cargo de virrey de Sicilia que ocupó entre 1671-1673. Por su apoyo incondicional a la causa borbónica fue nombrado Mayordomo Mayor (1701), Ministro de la Junta de Gobierno (1702) y Caballero de la Orden del Espíritu Santo (1702) ${ }^{19}$. Como fue costumbre en la época entre las grandes familias de la nobleza, durante su estancia italiana se escribió un libro apologético que incluía un extenso árbol genealógico de las ramas familiares y dos grabados, uno con el escudo de los marqueses de Villafranca del Bierzo (Figura 4) y un retrato del VII marqués, realizados por Agnello Portio ${ }^{20}$. Para ello contó con la colaboración del mejor genealogista y cronista real, Luis de Salazar y Castro, quién partiendo del estudio de sus archivos personales le escribió la historia familiar. El trabajo titulado Justificación de la grandeza de primera clase que pertenece a Don Fadrique de Toledo-Osorio, VII marqués

${ }_{15}$ Aldea Vaquero, 2017: 15-32.

16 Carriazo Rubio, 2013: 41-64.

17 Postigo Castellanos, 2001: 331-380.

18 Mercure historique et politique contenant l'etat present de l'Europe, ce qui passe dans toutes les cours, l'interêt des princes, leurs brigues et generalement tout ce qu'il y a de curieux pour le mois de juin de 1702, 1702: 747.

${ }^{19}$ Fernández Vázquez, 2007: 15.

${ }^{20}$ Sosa, 1676: 53-70. Ver Palmer, 2009: 401-421. 
de Villafranca, publicado en Madrid en $1704^{21}$, pretendió explicitar sus méritos, familiares y propios, para conseguir la Grandeza de España de primera clase ${ }^{22}$.

Su sucesor, José Fadrique Álvarez de Toledo Osorio (1658-1728), VIII marqués, contrajo matrimonio en 1683 con Catalina de Moncada y Aragón, IX duquesa de Montalto ${ }^{23}$. Debido a sus problemas físicos, desistió de la carrera militar y estuvo en la corte donde fue Gentilhombre de Cámara del Príncipe de Asturias, Mayordomo Mayor (1675) y Gentilhombre de la reina Mariana de Austria. Por su parte, Catalina de Moncada y Aragón (1665-1727) era hija de Fernando de Aragón Moncada, VIII duque de Montalto, y de doña María Teresa Fajardo, VII marquesa de los Vélez. Por tradición familiar estuvo vinculada a la corte madrileña tanto por los cargos que ejercieron los miembros masculinos de ambas casas como por la relación de las mujeres de la casa de Montalto y de los Vélez con las reinas de España ${ }^{24}$.

La ascendencia social y económica de ambas familias justificó las estrictas disposiciones establecidas en las capitulaciones matrimoniales de la pareja ${ }^{25}$. El convenio, firmado en Madrid el 24 de octubre de 1682 entre los padres de los contrayentes, fijaba las bases económicas por las que se regiría el matrimonio. El acuerdo iba acompañado de un censo de 140.000 escudos perpetuos y redimibles, impuesto por el duque de Montalto a su favor y al del futuro marido. La novia aportaba como dote 7.000 ducados de plata anual, moneda de Sicilia, de los cuales 4.000 serían para ella y el resto para su padre. Por su parte, el padre del novio se ofrecía a dar casa, mesa, caballería, criados, etc. y en caso de dividirse la dote, el marqués contribuiría a la manutención con 8.000 ducados al año. Se dispuso la parte económica correspondiente a la viudedad (6.000 ducados sobre todos los estados y en cada uno de ellos) y las condiciones de vivienda que en principio se establecía en casa de los duques de Montalto a menos que por voluntad de los contrayentes desearan vivir separados o con sus padres, concediéndoles 12.000 pesos a cada uno por mesadas para su descendencia además de todo lo necesario para su manutención.

${ }^{21}$ Biblioteca Nacional de España (BNE), Sig. 3/20357. Real Academia de la Historia (RAH), Sign. 9/295 fo 104. Colección Salazar y Castro.

22 Existe otra versión de 1694, ver Franco Silva, 1996.

${ }^{23}$ Ver Sánchez Ramos, 2005: 31-50.

${ }^{24} \mathrm{Su}$ abuela, Catalina de Moncada y Castro, VII duquesa de Montalto, jugó un papel relevante en la corte al ser dama de la reina Isabel de Borbón y su madre María Teresa Fajardo de Requesens fue aya del rey Carlos II además de Camarera Mayor de la reina Mariana de Austria. Ver Pilo, 2008: 38-70.

25 Archivo Fundación Casa Ducal Medina Sidonia (AFCDMS), Villafranca, Legajo, 440, 24 de octubre de 1682. Capitulaciones matrimoniales del Excmo. Sr. don Fadrique Alvarez de Toledo Osorio y la Excma. Sra. Doña Catalina de Moncada y Aragón. 
Herederos de dos grandes casas, el matrimonio tuvo una relevante colección de pintura y tapices, parte de ella procedente de los duques de Montalto. Catalina de Moncada se dedicó a administrar los bienes de las dos casas debido a la precaria salud de su marido. Mantuvo relaciones constantes con Sicilia donde conservaba sus feudos y de donde le enviaban objetos preciosos hasta un año antes de su muerte. Entre ellos citamos diferentes sedas y telas además de una "imagen de Nuestra Señora que sostiene una pililla de agua bendita y dos ramilleteros por ser de lo más primoroso que labran aquí los plateros" ${ }^{26}$. Catalina de Moncada percibía de sus estados sicilianos una renta anual de 7.000 escudos, lo que no le impidió pleitear con el duque de San Giovanni, Ignacio de Moncada y de la Cerda (1646-1712), sobre la pertenencia de los estados de Montalto en la isla. También se ocupó de sus feudos castellanos como se deduce del Memorial de Cuentas de la Colegiata de Villafranca del Bierzo ${ }^{27}$. Según dicho Memorial, la Colegiata quedó en estado ruinoso tras el incendio sufrido en los primeros años del siglo XVIII, encargándose la marquesa de iniciar su reconstrucción a partir de 1725. En ese año, siguiendo sus órdenes se procedió a la demolición de lo que estaba dañado en el edificio cuyo coste total ascendió a 13.651 reales $^{28}$. La obra finalizó en 1757, una vez ya muerta Catalina, importando los gastos que aportó 522.026 reales (Figura 5).

El hijo de este matrimonio, Fadrique Vicente de Toledo Osorio y Moncada (1686-1753), IX marqués de Villafranca del Bierzo, IX marqués de los Vélez contrajo matrimonio el 11 de septiembre de 1713 con Juana Pérez de Guzmán, hija del XII duque de Medina Sidonia, lo que acrecentó la riqueza y el poder de la casa. Sus virtudes quedaron expuestas en el texto impreso que se hizo con motivo de las solemnes exequias que tuvieron lugar en la villa de Matilla de Arzón (Zamora) en 1753 cuyo sermón corrió a cargo de padre José Gutiérrez ${ }^{29}$ (Figura 6). Vinculado a la corte, fue Gentilhombre de Cámara del rey (1720) y Mayordomo Mayor de la reina viuda Mariana de Neoburgo. Fiel al rey Felipe V, fue nombrado Ministro de Guerra en 1727 y Consejero de Estado en 1732. Fernando VI, correspondiendo a los buenos servicios prestados a su padre, le hizo Mayordomo Mayor en 1742, concediéndole el Toisón de Oro en 1750 y haciéndolo Caballero de la Orden del Espíritu Santo en 1751.

Por primera vez se favorecía a un miembro de la familia con el Toisón, una de las distinciones más relevante y distinguida de Europa desde su fundación en

26 AFCDMS, Moncada, Legajo 382. Correspondencia Palermo, 28 de junio de 1726.

27 Campos Sánchez-Bordona, 2000: 100-116. Fernández, 2001: 652-672.

${ }_{28}$ García Tato, 2007: 101-132.

${ }^{29}$ El impreso se conserva en el AFCDMS, Villafranca, Legajo, 1656. Sermón en las solemnes exequias del Excmo. Sr. D. Fadrique Vicente Álvarez de Toledo, marqués de VillaFranca de los Vélez, duque de Montalto, celebradas en su villa d Matilla de Arzón predicado por el P. M. Fr. Joseph Gutierrez... 
$1429^{30}$. Desde el siglo XVI, el Toisón de Oro les fue otorgado a algunos miembros de la alta nobleza española, la mayor parte de ellos Grandes de España ${ }^{31}$. Felipe V asumió la jefatura y la soberanía de la Orden al ser proclamado rey de España tras la paz de Utrecht de $1713^{32}$. Muchos nobles españoles que fueron fieles a la causa borbónica se les recompensó con el Toisón, tal fue el caso de los dos miembros del marquesado de Villafranca del Bierzo: el citado Fadrique Vicente IX marqués (otorgado en 1750) y Antonio Álvarez de Toledo Osorio (1716-1773), X marqués (otorgado en 1753).

Por este motivo, encargó un collar que se hizo en Madrid el 22 de mayo de 1750 según el diseño del platero Joseph Calbo, al que se le pagaron 2.200 reales de vellón ${ }^{33}$ (Figura 7). La joya fue utilizada para su investidura cuyo ceremonial era sumamente complejo y donde los símbolos eran esenciales, destacando el papel que jugaba el collar con su insignia ${ }^{34}$. La alhaja se componía de una pieza de plata con figura almendrada, eslabones con reverso liso y pulido blanco y dorado. El asidero de los eslabones era de plata guarnecida con diecisiete diamantes y se adornaba con cintas, hojas, florecitas, engastes y cartones. En la parte inferior llevaba una pieza de oro, que formaba las llamas, esmaltada a dos haces de rojo. En el reverso, la chapa del medio se esmaltó de azul transparente y por la cara llevaba un engaste de plata con un diamante. De las llamas colgaba el cordero de oro, por el un lado provisto de diamantes y por el otro cincelado, guarnecido todo con doscientos cincuenta y tres diamantes. Fue valorado por el tasador de la reina, Francisco Beltrán de la Cueva el 13 de mayo de 1751 en 52.998 reales de vellón. A esta cantidad se le añadió el valor del oro de las llamas y el cordero más el valor de la plata, tasados en 374 reales. Francisco Beltrán de la Cueva fue

${ }^{30}$ Ceballos-Escalera y Gila, 2000: 376-401. Martínez-Correcher y Gil, 2011: 45-75.

${ }^{31}$ Carlos V celebró un capítulo de la orden en Barcelona (1517) y otorgó la orden a los duques de Alba, de Escalona, del Infantado, de Frías, de Béjar, de Nájera, de Cardona, al conde de Melgar y al marqués de Astorga.

${ }^{32}$ Gijón Granados, 2009: 158-171.

${ }^{33}$ AFCDMS, Villafranca, Legajo 416. Inventario de todos los bienes libres y vinculados que quedaron por el fallecimiento de D. Fadrique Vicente Alvarez de Toledo $9^{\circ}$ marqués de Villafranca el día 1 de noviembre de 1753, La tasación la realizó Francisco Beltrán de la Cueva. En el recibo del platero Joseph Calbo dice textualmente "Memora de un toisón que he hecho para el Excmo. Marques de Villafranca el cual tiene diamantes setenta, a diez reales de sentar cada piedra importa 700 reales, pesa el oro de dicho toisón seis ochavas y media a veinte pesos la onza corresponde pesos efectivos 16 pesos y dos de plata que hacen 244 reales de vellón. Pesa la plata de dicho eslabón 5 ochavas y media que importo 131 reales, de hechura de las llamas y cordero 190 reales, total 1147 reales de vellón. He recibido de orden del Excmo. Sr marques de Villafranca duque de Montalto y marques de los Vélez mi señor y por mano de D. Matheo Rodríguez los mil y ciento cuarenta y siete reales de vellón de esta cuenta y por la verdad lo firmo en Madrid a 13 de mayo de 1751".

${ }^{34}$ Mínguez, 2011: 11-37. 
uno de los plateros de mayor significado en el Madrid de la época, quién ejerció el cargo de contraste de Villa entre 1742 a $1754^{35}$.

El IX marqués de Villafranca del Bierzo poseyó una importante colección de objetos artísticos según se deduce de sus inventarios ${ }^{36}$. Se componía de pinturas, muebles, joyas, tapices, coches de caballos y sillas de montar que manifestaba el alto nivel social y económico de la familia. Se conservaba en el palacio que tenía la familia en Madrid en la calle Don Pedro, del barrio de San Andrés (hoy es la sede de la Real Academia de Ingeniería) (Figura 8) muy cerca de la mansión que poseía otra de las familias nobiliarias de mayor relevancia en España, los Mendoza, duques del Infantado ${ }^{37}$. Parte de la colección procedía de la Casa de Montalto ya que el IX marqués era bisnieto de Luis Guillermo de Moncada (1614-1672), VII duque de Montalto gran coleccionista de ascendencia siciliana que trabajó para la monarquía hispánica, muriendo en Madrid en $1672^{38}$. De hecho, parte de los bienes procedentes de esa colección se vincularon posteriormente al mayorazgo de los Villafranca como se deduce del inventario citado. Entre ellas cabe destacar la extraordinaria colección de tapices que encargó el cardenal Moncada, terminada por su único hijo Fernando de Aragón y Moncada (1644-1713).

Varios tapices vinculados al mayorazgo de Villafranca del Bierzo procedían de la citada casa. Se relacionaron doce reposteros finos de Bruselas con las armas de la Casa de Moncada, un dosel de tapicería de Bruselas con un dibujo de la Fama en el centro y cenefas en los lados, una serie de seis tapices de Bruselas que representaban la historia de la Casa de Moncada y seis lienzos pintados al óleo que representaban la misma historia que contenían los tapices ${ }^{39}$. También vinculados constaban nueve tapices representando la Historia de Alejandro que según cita el inventario estaban ya "muy maltratados" y dos sobrepuertas, calificadas de "inservibles", éstos procedentes de la colección de los marqueses de Villafranca del Bierzo porque aparecen en el inventario de Pedro de Toledo Osorio, V marqués de este título (1546-1627) y fueron encargados por su abuelo homónimo ${ }^{40}$. El maestro tapicero, Antonio Morodo, los tasó en 20.590 reales. La colección se completaba con otros tapices sin vincular: cinco de fábrica fina de Amberes que representaban la Historia de Ciro (valorados en 7.312 reales), diez reposteros de 12-15.

${ }^{35}$ Cruz Valdovinos, 2003: 129-143. Martín García, 1991: 17-21. Aranda Huete, 1999:

${ }^{36}$ AFCDMS, Villafranca, Legajo 416. Inventario de todos los bienes libres y vinculados que quedaron por el fallecimiento de D. Fadrique Vicente Alvarez de Toledo $9^{\circ}$ marqués de Villafranca el día 1 de noviembre de 1753.

37 Mediero Velasco, 2012: 48-53.

${ }^{38}$ Sobre las colecciones de los duques de Montalto ver Scalisi, 2006; 2008. Halcón/ Herrera García, 2016: 113-139. Gil Saura, 2018: 109-128. López Conde, 2018: 221-236.

${ }^{39}$ Delmarcel/García Calvo/Brosens, 2010: 284-315.

${ }^{40}$ Campos Sanchez-Bordona, 2008: 4. 
Bruselas, entretejidos con oro y plata con escudos de armas en medio guarnecidos con culebras, óvalos y figuras en las cenefas (valorados 6.080 reales), seis tapices de Mesina, bien conservados, que representaban seis sacramentos (valorados en 5.280 reales). La valoración total de tapices ascendió a 39.262 reales de vellón.

Otros bienes vinculados procedentes de Moncada fueron dieciocho estatuas de bronce doradas, de medio cuerpo, que representaban a los señores de la casa con pedestales de madera y pies de bronce dorados ${ }^{41}$. Pinturas de ocho reyes y una reina de la Casa de Moncada con una alegoría de la envidia en la parte inferior, veintinueve cuadros con escenas de la Vida de Jesucristo, Vida de la Virgen, una del Éxtasis de María Magdalena, la Muerte de Caín, etc., veinticuatro pinturas con los Misterios del Credo, veinticuatro enconchados con escenas de la Vida de la Virgen, una pintura de Santa Isabel con el Niño Jesús y San Juan. Se vinculó también la lámina de relieve de plata y bronce dorado que representaba a Luis Guillermo de Moncada vestido de cardenal, marco de madera dorada y tallada rematado por dos águilas y corona de bronce dorado, veintiséis láminas de pintura en cobre con la historia de la Casa de Moncada, cincuenta y dos láminas de pintura en cobre de los retratos de todos los señores de la casa de Moncada salvo uno que representaba las armas de la casa. Estas láminas fueron las que realizó el grabador flamenco Juan Felipe Jansen para ilustrar el libro de Giovanni Agostino della Lengueglia salvo la de Catalina de Moncada que realizó Pedro de Villafranca ${ }^{42}$.

Entre los bienes no vinculados figura la colección de pinturas, compuesta en su mayoría por pintura de carácter religioso como era habitual en la época. Entre ellas mencionamos cientos de cuadros de vidas de santos y misterios sagrados, una pintura de la Virgen de los Remedios, otra de San Juan, de San Nicolás de Bari, de Cristo con el cordero al hombro, varias pinturas que representan a la Virgen de Belén, otra pintura de Jesús, la Virgen y San José, etc. que se valoraron entre 120 y 200 reales cada una. Tradicionalmente, los marqueses de Villafranca del Bierzo fueron muy devotos de la Virgen de los Remedios como informa fray Geronimo de Sosa en el libro sobre la familia, por lo que existieron en la colección varias obras dedicadas a esta advocación ${ }^{43}$. Algunas pinturas hacen referencia a sus autores como la Inmaculada Concepción de mano del padre fray Francisco Almendros, dos pinturas que representaban respectivamente el Nacimiento de Cristo

${ }^{41}$ AFCDMS, Villafranca, Legajo 416. Inventario de todos los bienes libres y vinculados que quedaron por el fallecimiento de D. Fadrique Vicente Alvarez de Toledo $9^{\circ}$ marqués de Villafranca el día 1 de noviembre de 1753. Algunos de estos bronces aparecen en la lámina de Juan Felipe Jansen que representa a Giovanni Agostino della Lengueglia, 1657, para ilustrar el libro I ritratti della prosapia et heroi Moncada impreso en Valencia en el citado año.

${ }^{42}$ Sobre estos grabados Halcón/Herrera García, 2016: 120-122.

${ }^{43}$ Sosa, 1676: 35. 
y El Diluvio de Jacopo Bassano, valoradas en 4.000 reales $^{44}$, una pintura sobre tabla de la Virgen y el Niño "original de Alberto Durero" tasada en 1.500 reales $^{45}$, un San Juan Bautista de la escuela de Rafael valorado en 6.000 reales $^{46}$ y una pintura que representaba el Misterio de la Purificación de escuela flamenca tasada en 600 reales, procedente de la colección de Villafranca del Bierzo. Una de las pinturas de Bassano, El Diluvio, pudiera ser la que poseyó el conde de Monterrey, ya que parte de esta colección entró a formar parte de la colección de la casa de Alba que ostentaron ese título ${ }^{47}$. Entre las pinturas con autor figuran dos que adornaban sendos relojes de luz "de mano de Jordán" (Luca Giordano) tasados en 1.440 reales, ambas representaban las fábulas de la Fragua de Vulcano ${ }^{48}$. Un reloj tenía la caja de ébano, concha y palo santo, remates y pies de bronce, tasado en 600 reales mientras que el otro, con caja de ébano negro y remates de bronce, se valoró en 840 reales. La tasación de las pinturas la hizo Antonio González Velázquez, pintor de Cámara y las cajas y maquinarias del reloj el maestro relojero Fernando Miset por un total de 13.400 reales.

Como fue costumbre en la época, la colección contó con copias de originales como la Virgen con el Niño "copia de Anibal" valorada en 300 reales (copia de un original de Annibale Caracci), otra pintura de La Virgen con el Niño y San Juan "que es copia de Rafael" tasada en 200 reales $^{49}$, copia de una de las variadas versiones que tiene el pintor sobre el tema ${ }^{50}$ y un Nacimiento de Cristo copia de Correggio, tasado en 500 reales, una Virgen el Niño y San Juan con un marco ancho tallado y dorado "copia de Rafael" tasado en 600 reales y tres pinturas sobre cobre representados dos batallas y unos pasajeros bebiendo de "la escuela de David Teniers" tasadas en 500 reales cada una ${ }^{51}$. La existencia de las copias de grandes maestros y de cuadros asignados a varias escuelas pone de manifiesto la importancia que tuvo en Madrid desde el siglo XVI la existencia de ese tipo de pintura y la preferencia de la nobleza por cuadros de procedencia sobre todo italiana que encargaban a copistas ${ }^{52}$. El caso de las copias de Rafael fue paradigmático así

${ }^{44}$ Falomir, 2001: 88-89. Ruiz Manero, 2001: 44-49. Luna, 1971: 323-336.

45 Existe un original de Durero con este mismo tema en el Kunsthistorisches Museum, Wien y en la Galleria degli Uffizi, Florencia.

${ }_{46}$ Un original de este mismo tema se conserva en el Musée du Louvre.

${ }^{47}$ Falomir, 2001: 90-91.

48 Pérez Sánchez/Galasso/Ferrari, 2002: 298. Existen pinturas similares como la como la existente en el Hermitage Museum de San Petesburgo y en España tenemos el ejemplo en los amores de Venus y Vulcano del Palacio de la Zarzuela de Madrid (cat. R, 82).

${ }^{49}$ Posiblemente una copia de la Virgen del Prado conservada en el Kunsthistorisches Museum, Wien.

${ }^{50}$ Sobre la relevancia de las copias de Rafael en España ver: Ruiz Manero, 1992.

${ }^{51}$ David Teniers tiene varias pinturas de escenas de tabernas. En Madrid, hubo varias en las colecciones reales que se conservan en el Museo del Prado y en el Palacio Real,

52 García Cueto, 2017: 52-67. 
como la aparición de elementos compositivos ideados por este pintor que puede verse en obras de pintores españoles del siglo $\mathrm{XVI}^{53}$. Muchos de los grandes coleccionistas españoles del siglo XVII que tuvieron cargos en Italia poseyeron originales o copias del pintor de Urbino como el VII conde de Lemos, el III duque de Alcalá o el I duque de Medina de las Torres ${ }^{54}$.

Aunque no se hace mención a las pinturas de Procaccini que formaron parte de la colección de los Villafranca desde comienzos del siglo XVII, posiblemente las seguirían conservando pues se conoce que todavía en el último cuarto del siglo XVIII las mantenían ${ }^{55}$. El capítulo de pinturas profanas, menos numerosa que las religiosas, destacamos una serie de pinturas de carácter mitológico sin especificar, seis bodegones, cuatro cuadros grandes de batallas, cuatro pinturas sobre cristal de los cuatro elementos de escuela napolitana que curiosamente están calificadas como "deshonestas" aunque no hace mención al contenido de las figuras y que fueron tasados a un precio muy elevado (1.000 reales cada una). La tasación la hizo el pintor de corte Antonio González Velázquez (1723-1794), valorando las pinturas en 23.609 reales y las pinturas sobre tabla en 26.920 reales $^{56}$.

Como correspondía a un personaje de la alta nobleza vinculado a la corte, un capítulo importante dentro de la colección lo constituyeron los coches, berlinas y sillas de mano, tasados por el maestro de coches Joseph Dorado, que adquirieron una altísima cifra dentro de la valoración total de los bienes ${ }^{57}$. Entre los coches, destaca una bávara dorada (22.000 reales), una berlina dorada con sus molduras doradas (4.000 reales), un forlón con molduras doradas (14.000 reales), otro forlón caja verde y dorada (15.000 reales), una balandra de secretos (2.000 reales), una chaparra color hoja de oliva (1.700 reales), un coche verde forrado de vaqueta con tres vidrios (1.500 reales), un juego verde con molduras doradas (1.900 reales), un coche chaparra de quebranto color hoja de oliva oscuro (4.000 reales) y una berlina (1.800 reales $)^{58}$. Se relacionan otros coches de menor entidad como un carro con cuatro ruedas (400 reales) y un forlón caja azul con molduras doradas (4.000 reales) sumando la totalidad de los coches 77.800 reales ${ }^{59}$. Las sillas de mano fueron tasadas por el maestro de hacer sillas Valentín Díaz, destacando una silla de gala pintada y dorada (2.300 reales), otra silla de moda forrada con

${ }^{53}$ Mena Marqués, 1985: 11-28.

${ }^{54}$ Ruiz Manero, 1992: 12-14.

55 Bosch Balbona, 2016: 91-108.

${ }_{56}$ AFCDMS, Villafranca, Legajo 416, años 1750-1754. Inventario de todos los bienes libres y vinculados que quedaron por el fallecimiento de D. Fadrique Vicente Alvarez de Toledo $9^{\circ}$ marqués de Villafranca el día 1 de noviembre de 1753.

57 Atienza Medina, 2006: 197-202.

58 AFCDMS, Villafranca, Legajo 416. La tasación está firmada en Madrid el 9 de diciembre de 1753 por el maestro de coches Joseph Dorado.

59 Sobre el tema ver López Álvarez, 2007. Recio Mir, 2018: 209-226. 
terciopelo carmesí por dentro y por fuera adornos de talla dorada (2.500 reales), otra a la española (550 reales) y otra de vaqueta (500 reales). Parte de la colección de carruajes fue comprada directamente por el Caballerizo Mayor, Nicolás Coronel, cuya relación incluye un coche verde de mujer (1.800 reales), una berlina azul (1.700 reales), dos coches de camino (1.620 reales), una berlina verde con molduras doradas (1.350), dos berlinas abiertas (1.300 reales) y tres carros (1.200 reales).

Acorde con el gusto y refinamiento de la corte española de la segunda mitad del siglo XVIII, un capítulo relevante dentro de los inventarios lo constituyeron la plata y las joyas. La plata fue tasada por Lorenzo González Morano, tasador en el contraste en la que se incluyeron vajillas de plata, ensaladeras, mancerinas redondas, salvillas, azafates, jarros y cuberterías, valorado en 32.298 reales $^{60}$. Esta tasación se incrementó con ciento veinticuatro platos de plata más dieciocho mancerinas, dieciocho candelabros grandes, doce candeleros más otros seis más pequeños, terrinas, cazuelas, corbellas, tarros de plata, frascos, fuentes grandes y pequeñas, bandejas, alzaderas, vasos, cuberterías, valorado en 68.516 reales. La última tasación de la plata la realizó el ensayador Félix Leonardo de Nieva quién valoró la vajilla de plata más numerosa y rica compuesta por ciento treinta y dos platos de diferentes tamaños, ensaladeras, salvillas, aguaderas, palanganas y cuberterías en 257.541 reales $^{61}$.

Las joyas y alhajas fueron tasadas por Francisco Beltrán de la Cueva, destacando el altísimo valor de alguna de ellas. Las más relevantes y valoradas desde el punto de vista histórico y familiar fueron el Toisón completo con sus eslabones de oro guarnecido con 253 diamantes de diferentes tamaños (52. 998 reales); la guarnición de un espadín de punta, gancho y contera con 1.215 diamantes de diferentes tamaños (80.025 reales) y una joya grande de oro para el pecho en forma de burriel con diferentes hojas y engastes, ganchos y colgantes equipada con 171 diamantes y 19 esmeraldas de diferentes tamaños (73.524 reales). Se relacionan otras joyas como dos broches de oro compuestos de tres piezas cada uno con 216 diamantes rosas y 30 esmeraldas (24.783 reales); una gargantilla de oro compuesta por 17 piezas con 43 diamantes rosas y 18 esmeraldas (12.961 reales), una piocha de plata con el reverso liso compuesta de un lazo de cuatro hojas con un colgante abajo adornado con brillante y por arriba cinco plumas surtidas de diamantes y entre ellas otras seis plumas escarchadas guarnecidas con 89 diamantes (21.021 reales). Del resto de la valoración sobresalen dos hebillas de zapatos adornadas con diamantes tasadas (23.595 reales), un ojal para sombrero de plata

${ }^{60}$ AFCDMS, Villafranca, Legajo 416. La tasación está fechada el 10 de mayo de 1754. Sobre plateros y contrastes madrileños del siglo XVIII ver, Martín García, 1983: 25-30.

${ }^{61}$ AFCDMS, Villafranca, Legajo 416, año 1755, 6 de marzo de 1755. 
con su botón uno y otro guarnecidos con 48 diamantes (5.412 reales) más arracadas, sortijas, cruces, varios diamantes, etc. valoradas en 21.959 reales $^{62}$.

Dada la tradición de la nobleza hispánica de subastar los bienes no vinculados con el fin de pagar las deudas, el 17 de junio de 1752 se otorgaba en Madrid una escritura mediante la cual Antonio Álvarez de Toledo Osorio, duque de Fernandina, condescendiendo a la voluntad de su padre el IX marqués de Villafranca del Bierzo, se obligaba a satisfacer con sus bienes libres todas las deudas contraídas por aquel hasta el momento de su muerte ${ }^{63}$. El duque de Fernandina, ante los graves inconvenientes que este hecho le acarreaba, protestaba formalmente y declaraba que otorgaría escritura en cuanto a las mandas para satisfacer la voluntad de su padre sin ánimo de quedar ligado en forma alguna a la paga y satisfacción de las mandas del testamento.

La tasación de los bienes libres la hicieron varios especialistas: Santos Ramos, profesor de arquitectura y tallista de S. Majestad, quién hace constar que en el momento de valorar los bienes tenía 44 años y vivía en la calle de la Magdalena frente a la casa del marqués de Perales; Lorenzo Perero maestro cofrero de Cámara del rey que vivía en calle Mayor y el maestro carpintero Juan Peynado que vivía en las casas del marqués de la Vega del Pozo. El importe total del inventario de bienes vinculados y libres en el momento de la muerte del IX marqués(1XI-1753), ascendió a un total de 1.033.454 reales de vellón ${ }^{64}$. En la subasta de bienes se vendieron los no vinculados que fueron adquiridos, en su mayoría, a un precio inferior al tasado. Fue el caso de una colgadura de damasco comprada por un mercader de la calle de Alcalá en 4.500 reales, aunque estaba tasada en 12.000. La liquidación de la testamentaría se formalizó en Madrid el 26 de febrero de 1754 y en ella se declaró, además del día de su muerte (1-XI-1753), el lugar donde estaba sepultado: la bóveda de la iglesia de la Venerable Orden Tercera de Madrid, especificando que las misas que se celebraron en el convento de San Francisco el Grande.

El marquesado de Villafranca del Bierzo siguió vinculado a la corte madrileña a través del X marqués, Antonio Álvarez de Toledo Osorio (1716-1773) quién fue Gentilhombre de Cámara de Fernando VI y mayordomo de la reina Bárbara de Braganza. Sus máximas aspiraciones cortesanas las consiguió con el rey Carlos III que le nombró consejero de la Junta de Gobierno (1760) y presidente del despacho de Estado (1761). Por los servicios prestados a la monarquía hispánica, el rey le concedió el Toisón en 1763 y le hizo caballero gran cruz

${ }^{62}$ AFCDMS, Villafranca, Legajo 416, años 1750-1754. La tasación está hecha por Francisco Beltrán de la Cueva.

${ }^{63}$ AFCDMS, Villafranca, Legajo 416, escritura firmada ante Juan Manuel Auñon el 17 de junio de 1752.

${ }^{64}$ AFCDMS, Villafranca, Legajo 416, años 1750-1754. 
de la Orden de Carlos III ${ }^{65}$. En la primera mitad del siglo XVIII, la casa de Villafranca del Bierzo (ducado de Fernandina, principado de Montalbán y condado de Peña Ramiro) integraba a las casas nobiliarias de Montalto y Vélez, cada una de ellas, a su vez, con sus títulos anexos correspondientes (Principado de Paternó, ducado de Bivona, condado de Caltanissetta, condado de Collesano, condado de Adernó, condado de Esclafana, condado de Caltabellota procedentes de Montalto y marquesado de Molina, marquesado de Martorell procedente de los Vélez) lo que conllevó la acumulación de bienes muebles e inmuebles además de documentación ${ }^{66}$. El citado Antonio Álvarez de Toledo, X marqués de Villafranca del Bierzo y X marqués de los Vélez, con el fin de reunir todos sus enseres familiares se ocupó de trasladar, en 1755, los bienes muebles y archivo desde Murcia a Madrid donde tenía su domicilio particular de la calle Don Pedro ${ }^{67}$.

En el último cuarto del siglo XVIII, la colección artística se vio enriquecida por gajes del destino y favorables enlaces matrimoniales de los miembros de la casa de Villafranca del Bierzo, no siendo ajena a este crecimiento la vinculación de sus miembros a la corte. La máxima acumulación de títulos y bienes se viviría en la figura del XI marqués, José Álvarez de Toledo Osorio y Gonzaga (17561796) quién en 1775 se convirtió en XIII duque consorte de Alba, anteponiendo este título a todos los demás, y en 1779 heredaría de su tío segundo, Pedro de Alcántara Pérez de Guzmán ((1724-1779), XIV duque de Medina Sidonia, dicho ducado debido a la falta de descendencia, convirtiéndose en el XV duque de Medina Sidonia más todos sus títulos agregados (condado de Niebla, marquesado de Cazaza).

La colección de los marqueses de Villafranca del Bierzo mantuvo su importancia hasta el siglo XVIII, en este sentido difiere de otras grandes colecciones españolas como las de Leganés, Carpio, Almirantes de Castilla, etc., que ya en esa centuria apenas si quedaban atisbos del esplendor que tuvieron, viéndose abocadas a su dispersión y venta. El caso de la extraordinaria colección del VII marqués del Carpio (1629-1687) se subastó en parte a su muerte, primero en Nápoles en 1687 y, posteriormente, en Madrid para saldar sus múltiples deudas ${ }^{68}$. La del I marqués de Leganés (1580-1655) que llegó a poseer un total de mil trecientas treinta y tres obras con pinturas flamencas, italianas y contemporáneas españolas corrió similar suerte. En parte fue haciendo donaciones en vida pero un relevante número de pinturas de subastaron y otras se perdieron ${ }^{69}$. La del X Almirante de Castilla (1625-1691), asiduo comprador en las almonedas madrileñas y gran

65 Válgoma, 1946: 57.

66 Álvarez de Toledo y Maura, 2003: 16-20.

${ }^{67}$ Beltrán Corbalán, 2014: 174-185. García Carballo/Madrazo García de Lomana/ Mato Miguel, 2009.

${ }_{68}^{6}$ Para el estudio más completo de esta colección y su bibliografía en Frutos, 2019.

${ }^{69}$ Pérez Preciado, 2010: 797-916. 
coleccionista de pinturas y esculturas, se dispersó primero a su muerte y posteriormente cuando le incautaron los bienes a su hijo Juan Tomás Enríquez de Cabrera (1646-1705), XI y último Almirante de Castilla, al defender la causa austríaca frente a la borbónica por lo que fue juzgado y condenado ${ }^{70}$. Aparte de la colección de Villafranca del Bierzo, en el siglo XVIII existieron otros notables coleccionistas en España que, aunque no tuvieron la relevancia de la anterior centuria, fueron dignas de mención como las del I marqués de la Ensenada (1702-1781), los duques de Osuna, los duques de Alba o Manuel Godoy (1767-1851) ${ }^{71}$.

Fecha de recepción: 22 de mayo de 2020.

Fecha de aceptación: 2 de mayo de 2021.

\section{BIBLIOGRAFÍA}

Agüero Carnerero, Cristina (2018): Los Almirantes de Castilla en el siglo XVII. Políticas artísticas y coleccionismo nobiliario, Tesis doctoral. Madrid: UNED, pp. 518-530.

Aldea Vaquero, Quintín (2004): “Un noble español del barroco. Don García de Toledo, VI marqués de Villafranca". En: Cuadernos de Historia del Derecho, pp. 15-32.

Álvarez de Toledo y Maura, Luisa Isabel (2003): Las casas incorporadas. Sanlúcar de Barrameda: Fundación Casas Ducal de Medina Sidonia.

Aranda Huete, Amalia (1999): La joyería en la corte durante el reinado de Felipe V e Isabel de Farnesio. Madrid: Universidad Complutense de Madrid.

Atienza Medina, Rafael (2006): "El carruaje como objeto de ostentación". En: Minervae Baetica, pp. 197-202.

Beltrán Corbalán, Domingo (2014): El archivo de la Casa de los Vélez. Historia, estructura y organización. Murcia: Universidad de Murcia.

Bosch Balbona, Joan (2007-2008): "Paul Bril, Wenzel Cobergher, Jacob Frankaert y Willen I van Nieulandt y los "Ermitaños" de Pedro de Toledo V marqués de Villafranca". En: Locus Amoenus, 9, pp. 127-154.

(2009): "Retazos del sueño tardorenacentista de don Pedro de Toledo Osorio y Colonna en el monasterio de la Anunciada de Villafranca del Bierzo". En: Anuario del Departamento de Historia y Teoría del Arte, 21, pp. 121-146. (2013-2014): "La fortaleza que quiso ser palacio. Noticia de Camillo Camiliani en España (1604)". En: Locus Amoenus, 12, pp. 79-106.

Bosch Balbona, Joan (2016): "Nápoles, Pozzuoli, Villafranca sin Pedro de Toledo” en Sánchez García, Encarnación (ed.), Rinascimento Meridionale.

\footnotetext{
${ }^{70}$ Agüero Carnerero, 2018: 518-530.

71 Jiménez-Blanco, 2013: 16-28
} 
Napoli ee il Viceré Pedro de Toledo (1532-1553). Nápoli: Tullio Pironti, pp. 653-705.

(2016): "Sobre el quinto marqués de Villafranca, Camillo y Giulio Cesare Procaccini”. En: Locus Amoenus, 14, pp. 91-108.

Brown, Jonathan (1995): El triunfo de la pintura. Sobre el coleccionismo cortesano del siglo XVII. Madrid: Nerea.

Burke, Marcus B./Cherry, Peter (1997): Collectios of paintings in Madrid (16011755). Los Ángeles (USA): The Getty Information Institute.

Campos Sanchez-Bordona, María Dolores (2008): "El gusto y el encargo artístico de los marqueses de Villafranca". En: Actas Congreso Internacional Imagen y Apariencia. Murcia: Universidad de Murcia, pp. 150-173.

(2000): "La Colegiata de Villafranca del Bierzo. De fray Martín de Santiago a Guillermo Casanova". En: El arte de la cantería. V Centenario del nacimiento de Rodrigo Gil de Hontañón. Santander: Centro de Estudios Montañeses, pp. 100-116.

Carriazo Rubio, Juan Luis (2013): "Genealogía de los señores de la Casa de Medinasidonia de Luis Salazar y Castro". En: Historia y Genealogía, 3, pp. 41-64.

Ceballos-Escalera y Gila, Alfonso (2000): La insigne Orden del Toisón de Oro. Madrid: Palafox y Pezuela, pp. 376-401.

Coniglio, Giuseppe (1984): Il viceregno di don Pedro di Toledo. 2 vols. Nápoles: Gianini.

Cruz Valdovinos, José Manuel (2003): "La platería en la corte madrileña de los Habsburgo a los Borbones". En: Estudios de Platería San Eloy. Murcia: Universidad de Murcia, pp. 129-143.

Delmarcel, Guy/Garcia Calvo, Margarita/Brosens, Koenraad (2010): "Spanish Family Pride in Flemish Wool and Silk: The Moncada Family and its Baroque Tapestry Collection”. En: Tapestry in the Baroque. New Aspects of Production and Patronage. New York: The Metropolitan Museum, pp. 284-315.

Estella, Margarita (2008): "La corte virreinal y su influencia en las artes. El mecenazgo de los Toledo”. En: Arte, poder y sociedad en la España de los siglos $X V$ a XX. Madrid: CSIC, pp. 219-232.

Falomir, Miguel (2001): Los Bassano en la España del Siglo de Oro. Madrid: Museo Nacional del Prado.

Fernández, Vicente (2001): Arquitectura religiosa en El Bierzo. Ponferrada: Instituo de Estudios Bercianos.

Fernández Vázquez, Vicente (2007): El señorío y marquesado de Villafranca del Bierzo a través de los documentos del archivo Ducal de Medina Sidonia. Ponferrada: Instituto de Estudios Bercianos.

Franco Silva, Alfonso (1996): La fortuna y el poder: estudios sobre las bases económicas de la aristocracia castellana (siglos XIV-XV). Madrid: Marcial Pons.

Frutos, Leticia de (2009): El templo de la Fama. Alegoría del marqués del Carpio. Madrid, Fundación Arte Hispánico. 
García Calvo, Margarita (2010): "Pedro de Toledo (1546-1627), V marqués de Villafranca del Bierzo, coleccionista de tapices". En: Archivo Español de Arte, 332, pp. 347-362.

García Carballo, Ángel/Madrazo García de Lomana, Gonzalo/Mato Miguel, Juan Francisco: La Real Academia de Ingeniería: historia del palacio de los marqueses de Villafranca. Madrid: Real Academia de Ingeniería.

García Cueto, David (2017): "Madrid como centro de copiado pictórico durante la fase final de la Unión Ibérica (1621-1640)". En: Revista Histórica da Arte, 7, pp. 52-67.

García Tato, Isidro (2007): "Un ejemplo de conflictividad eclesiástica: la Colegiata de Villafranca del Bierzo (siglos XVI-XIX)". En: Nobleza y aristocracia berciana: el marquesado de Villafranca. Ponferrada: Instituto de Estudios Bercianos, pp. 101-132.

Gil Saura, Yolanda (2018): "Giovanni Battista Morelli y el duque de Montalto, entre Roma, Valencia y la corte española" en Gómez Ferrer, Mercedes (coord..), Ecos culturales, artísticos y arquitectónicos entre Valencia y el Mediterráneo en época moderna, Valencia, Universitat de València, pp. 109-128.

Gijón Granados, Juan de A. (2009): La Casa de Borbón y las Órdenes Militares durante el siglo XVIII (1700-1809). Madrid, Universidad Complutense.

González Ramos, Ignacio (2007): "Raíces medievales del marquesado de Villafranca del Bierzo". En: Nobleza y Aristocracia berciana: el marquesado de Villafranca del Bierzo. Ponferrada: Instituto de Estudios Bercianos, pp. 3-35.

Halcón, Fátima/Herrera García, Francisco (2016): "Entre Sicilia y España: nuevas aportaciones a la colección artística de Luis Guillermo de Moncada, duque de Montalto (1614-1672). En: Anuario del Departamento de Historia y Teoría del Arte, 28, pp. 113-139.

Hernando Sánchez, Carlos José (1988): "Poder y cultura en el Renacimiento napolitano: la biblioteca del virrey Pedro de Toledo". En: Cuadernos de Historia Moderna, 9, pp. 13-33.

- (1988): Castilla y Nápoles en el siglo XVI: linaje, estado y cultura (15321553). Salamanca: Junta de Castilla y León.

—_: Política de Estado, clientelas y cultura en Nápoles bajo el virrey Pedro de Toledo. Madrid: Universidad Complutense, 1991.

_ (1993): "La vida material y el gusto artístico en la corte de Nápoles durante el Renacimiento. El inventario de bienes del virrey Pedro de Toledo". En: $\mathrm{Ar}$ chivo Español de Arte, 261, pp. 35-55.

Jiménez-Blanco, María Dolores (2013): El coleccionismo de arte en España. Una aproximación desde su historia y su contexto. Barcelona, Fundación Arte y Mecenazgo.

López Álvarez, Alejandro (2007): Poder, lujo y conflicto en la corte de los Austrias. Coches, Carrozas y sillas de mano, 1550-1700. Madrid: Polifemo. 
López Conde, Rubén (2018): "Un ciclo pictórico teresiano para el cardenal-duque de Montalto", En: Archivo Español de Arte, XIC, 363, pp. 221-236.

Luna, Juan José (1971): "Acotación a la serie "El Diluvio" de los Bassano". En: Archivo Español de Arte, 175, pp. 323-336.

Martín García, Fernando (1983): "Contrastes y marcadores de la platería madrileña en el siglo XVIII". En: Villa de Madrid, 78, pp. 25-30.

(1991): Catálogo de la Plata del Museo Municipal de Madrid. Madrid: Ayuntamiento de Madrid.

Martínez-Correcher y Gil, Joaquín (2011): "La Orden del Toisón de Oro y la Corona de España. Quinientos años de historia”. En: La Orden del Toisón de Oro y sus soberanos (1430-2011). Madrid: Fundación Carlos de Amberes, pp. $45-75$.

Mediero Velasco, Ma Isabel (2012): "El palacio de los marqueses de Villafranca”. En: Madrid Histórico, 41, pp. 48-53.

Mena Marqués, Manuel B (1985): "Presencia histórica de obras de Rafael en España”. En: Catálogo Exposición Rafael en España. Madrid: Museo Nacional del Prado, pp.11-28.

Mercure historique et politique contenant l'etat present de l'Europe, ce qui passe dans toutes les cours, l'interêt des princes, leurs brigues et generalement tout ce qu'il y a de curieux pour le mois de juin de 1702. La Haya: Chez Henri van Bulderen.

Mínguez, Víctor (2011): "El Toisón de Oro. Insignia emblemática y heráldica de la monarquía hispánica”. En: Zafra, Rafael/Azanza, José Javier: Emblemática trascendente. Hermenéutica de la imagen, iconología del texto. Pamplona: Universidad de Navarra, pp. 11-37.

Morán Turina, Miguel/Checa, Fernando (1985): El coleccionismo en España. De la cámara de las maravillas a la galería de pinturas. Madrid: Cátedra.

Palmer, Rodney (2009): "Vicerregal dedicates of Neapolitan Illustrated Books (1670-1707)". En: España y Nápoles. Coleccionismo y mecenazgo virreinales en el siglo XVII. Madrid: Centro de Estudios Europa Hispánica, pp. 401-421.

Pane, Giulio (1979): "Pietro di Toledo, vicer'urbanista". En: Napoli Nobilissima I, vol. XIV, pp. 81-95.

Pérez Preciado, Juan José (2010): El marqués de Leganés y las artes. Tesis doctoral. Madrid, Universidad Complutense de Madrid.

Pérez Sánchez, Alfonso/Gelasso, Giusseppe/Ferrari, Oreste (2002): Luca Giordano y España. Madrid: Patrimonio Nacional.

Pilo, Rafaella (2008): Juan Everardo Nithard y sus Causas no Causas. Razones y pretextos para el fin de un valimiento. Madrid: Sílex.

Postigo Castellanos, Elena (2001): "El cisma del Toisón. Dinastía y orden (17001748). En: Fernández Albadalejo, P. (ed.), Los Borbones. Dinastía y memoria de nación en la España del siglo XVIII. Madrid: Marcial Pons, pp, 331-380. 
Ramírez Ruiz, Victoria (2012): Las tapicerías en las colecciones de la nobleza española del siglo XVII. Madrid: Universidad Complutense.

Recio Mir, Álvaro (2018): “¿Qué Indias hay donde no hay coches?: el carruaje como objeto de análisis histórico y artístico en España y en la América virreinal". En: Laboratorio de Arte, 30, pp. 209-226.

Rubio Pérez, Laureano M. (2007): "Señoríos y régimen señorial en el reino de León, siglos XV-XIX”. En: Nobleza y Aristocracia berciana: el marquesado de Villafranca del Bierzo. Ponferrada: Instituto de Estudios Bercianos, pp. 57-84.

Ruiz Manero, José María (1992): "Pintura italiana del siglo XVI en España. Rafael y su escuela". En: Cuadernos de Arte e iconografía, 10, pp. 7-234.

(2001): Los Bassano en España. Madrid: Museo Nacional del Prado,pp. 4448. Sánchez Ramos, Valeriano (2005): "Sangre, honor y mentalidad nobiliaria: la casa de Fajardo entre dos siglos". En: Revista Velezana, 24, pp. 31-50.

Scalisi, Lina (ed.) (2006: La Sicilia dei Moncada. Catania: Sanfilippo Editore.

-(ed.) (2008): La Sicilia degli heroi. Catania: Sanfilippo Editore.

Serrera, Juan Miguel (2001): "La historia del coleccionismo y mecenazgo en la España moderna". En: Bernardo Ares, J. M. de (ed.), El hispanismo angloamericano: aportaciones, problemas y perspectivas sobre Historia, Arte y Literatura española. Siglos XVI-XVII. T. II. Córdoba: Cajasur, pp. 1431-1453.

Sosa, fray Geronimo de (1676): Noticia de la gran Casa de los marqueses de Villafranca y su parentesco con los mayores de Europa...del Excelentísimo Señor D. Fadrique de Toledo Osorio, séptimo marques de esta casa... Nápoles: Novelo de Bonis.

Urquízar Herrera, Antonio (2007): Coleccionismo y nobleza. Signos de distinción social en la Andalucía del Renacimiento. Madrid: Marcial Pons.

Válgoma, Dalmiro de la (1946): La nobleza de León en la Orden de Carlos III. Madrid: CSIC. 


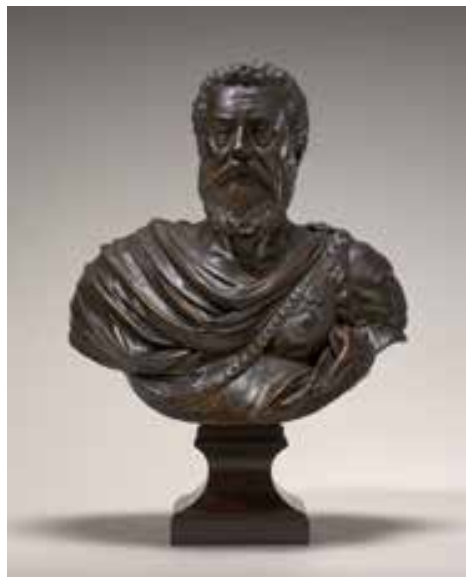

Figura 1. Anónimo, Pedro de Toledo (1484-1553), Washington, National Gallery of Arts.

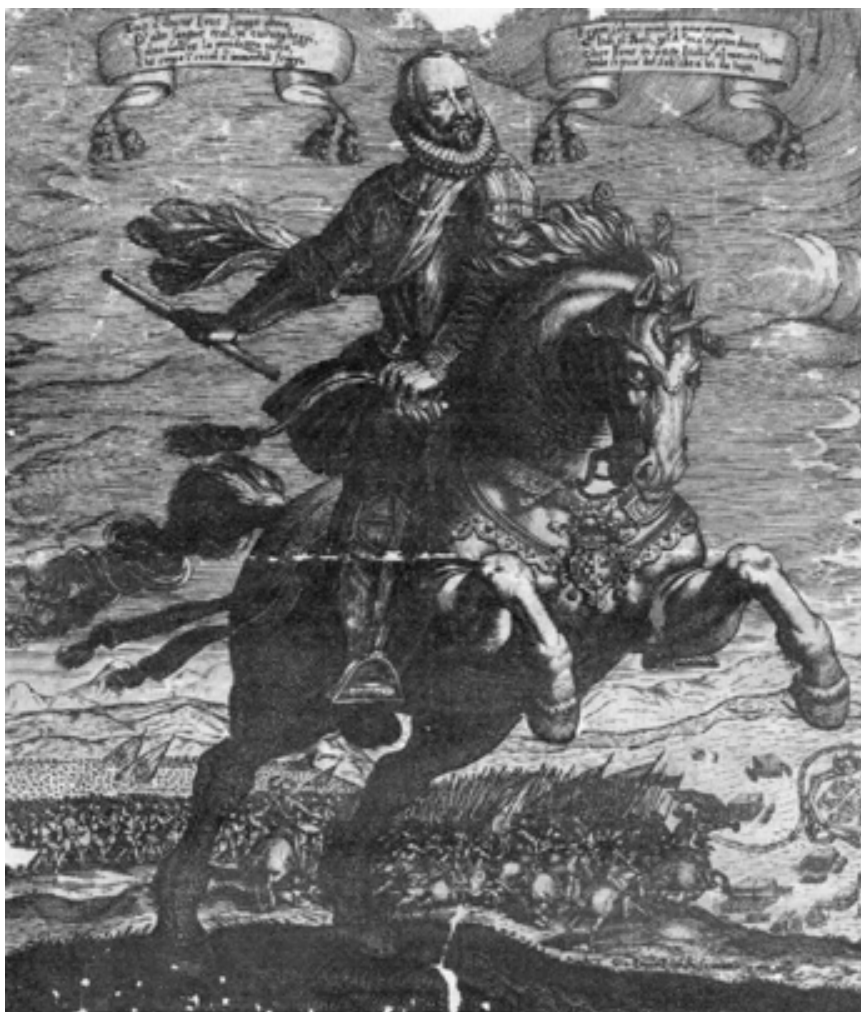

Figura. 2. Gian Paolo Bianchi, Retrato ecuestre de

Pedro de Toledo Osorio, V marqués de Villafranca del Bierzo, 1629, Madrid, Biblioteca Nacional de España. 


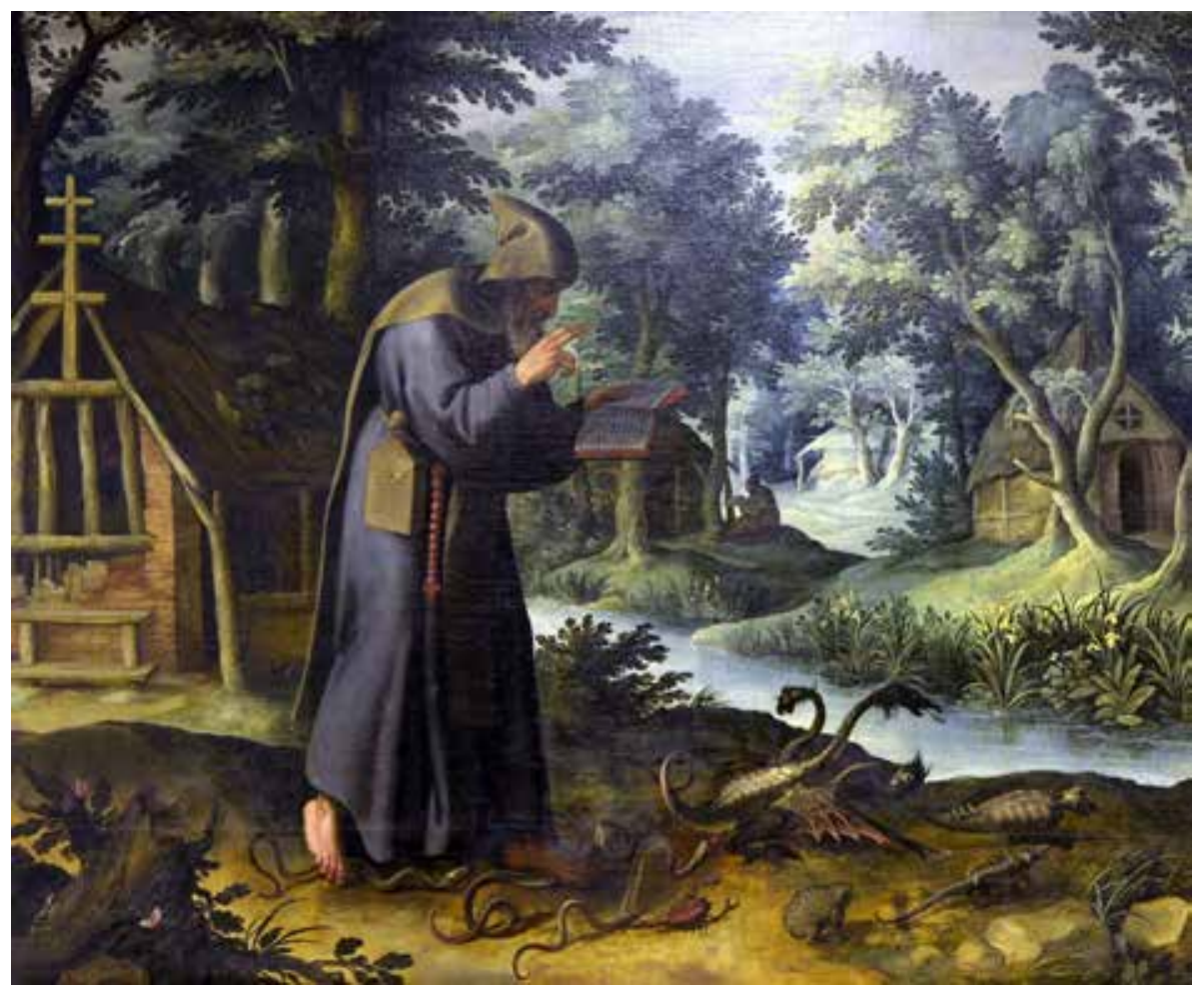

Figura 3. Paul Bril, Wenzel Cobergher, Jacob Frankaert y Willem I van Neuland, Dídimo el Ciego, Villafranca del Bierzo, Monasterio de la Anunciada. 


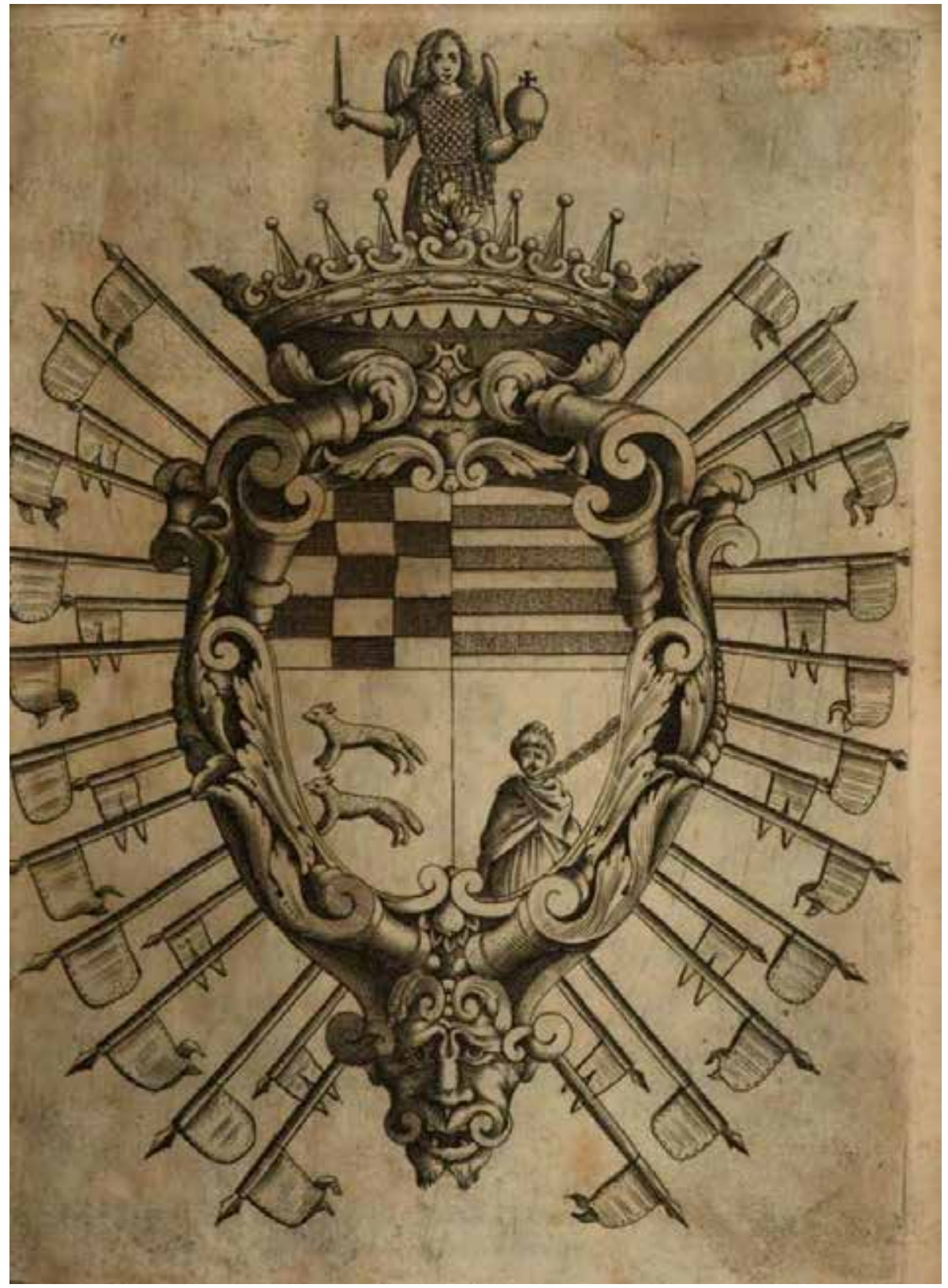

Figura 4. Fray Geronimo de Sosa, Noticia de la gran casa de los marqueses de Villafranca y su parentesco con las mayores de Europa... Nápoles, 1676, Escudo de armas de los marqueses de Villafranca del Bierzo. 


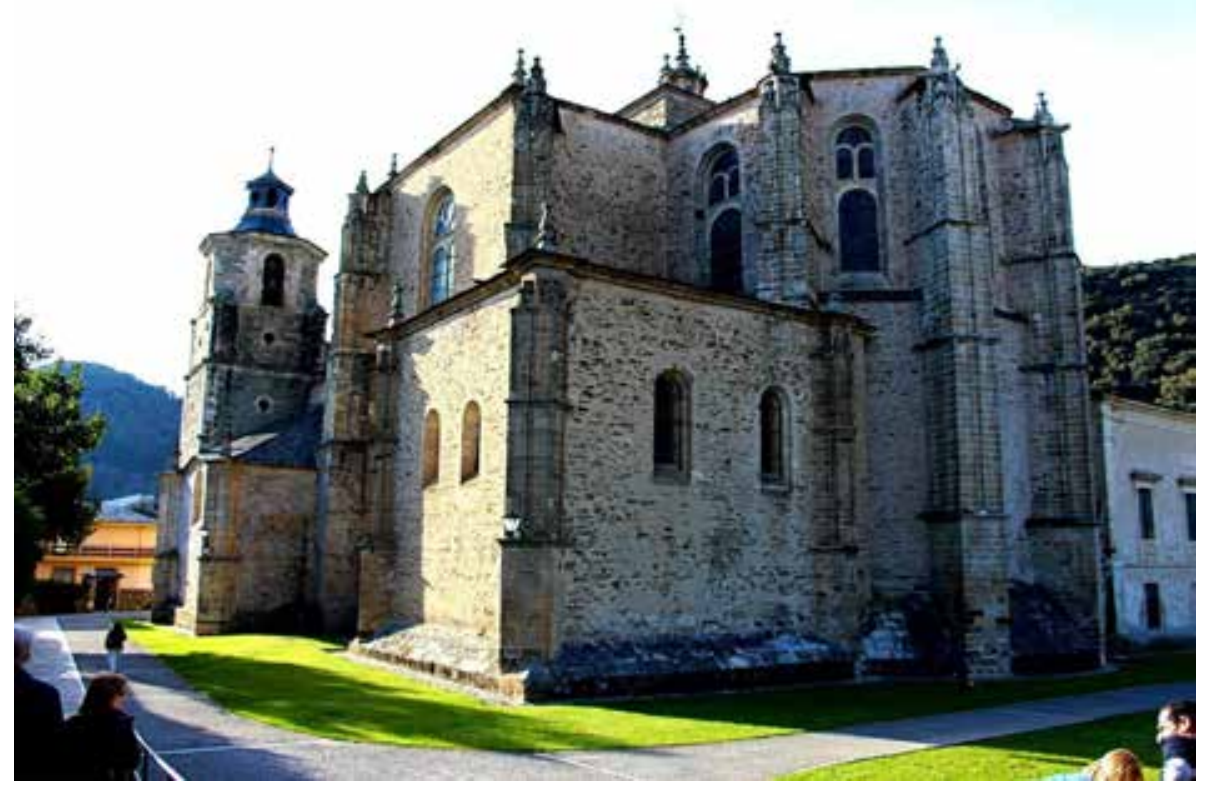

Figura 5. Vista de la colegiata de Villafranca del Bierzo. 


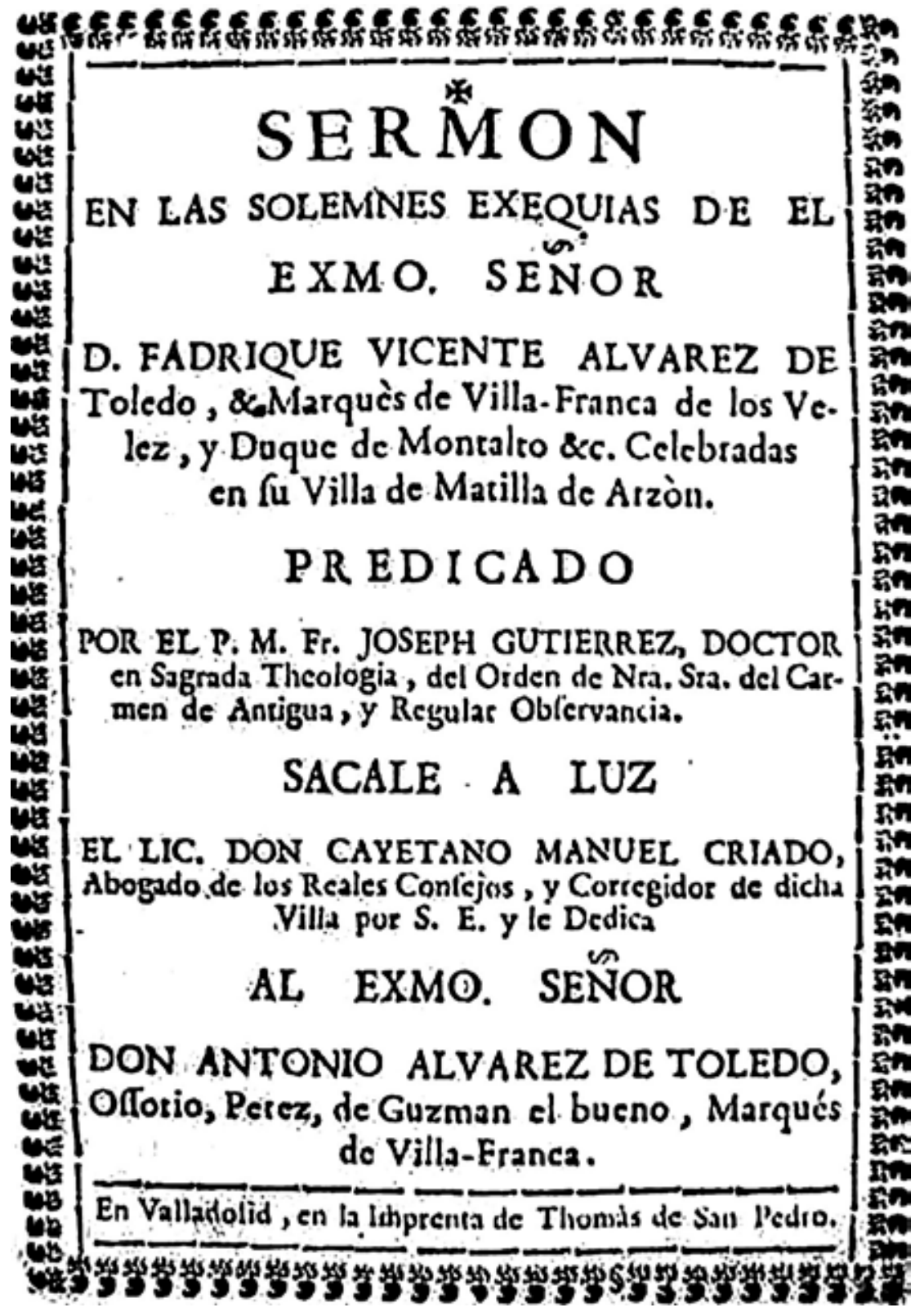

Figura 6. Sermón en las solemnes exequias del Ecmo. Sr. Don Fadrique Vicente Álvarez de Toledo...Valladolid, 1753, ACDMS. Villafranca, Leg. 1656. 


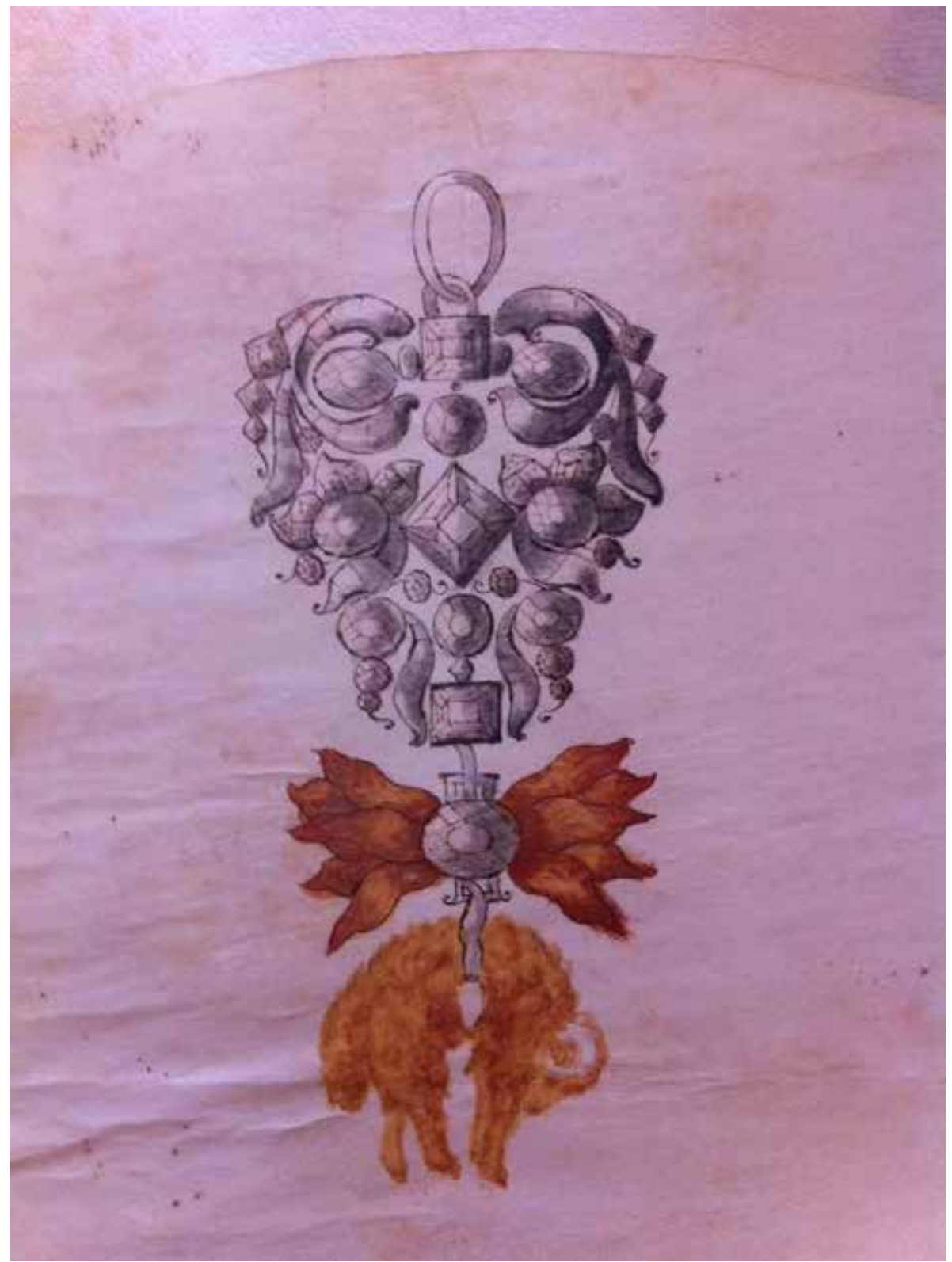

Figura 7. Josph Calbo. Dibujo del Toisón de Oro, AFCDMS, Legajo, 476, año 1750. 


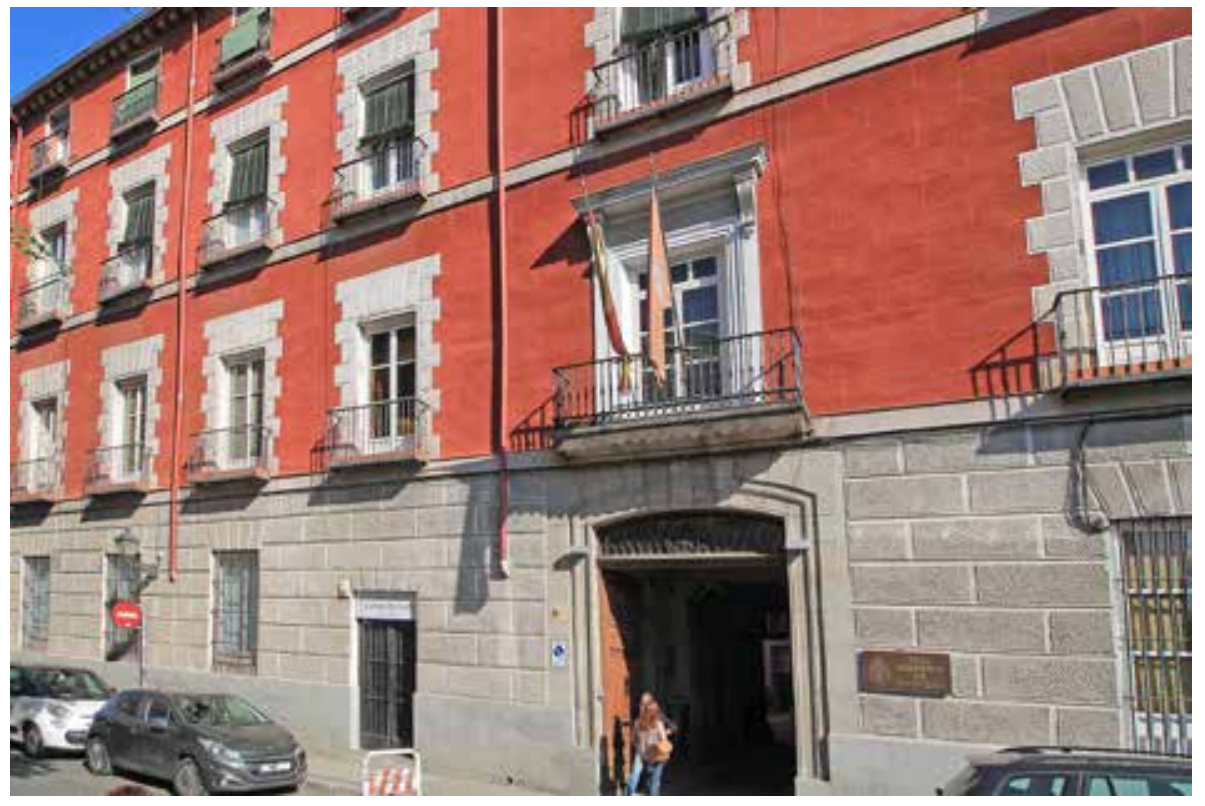

Figura 8. Palacio de los marqueses de Villafranca del Bierzo (hoy Real Academia de Ingeniería), Madrid. 